\title{
UCLA
}

Mester

Title

¿Qué es lo neofantástico?

Permalink

https://escholarship.org/uc/item/7j92c4q3

Journal

Mester, 19(2)

Author

Alazraki, Jaime

Publication Date

1990

DOI

10.5070/M3192014104

Copyright Information

Copyright 1990 by the author(s). All rights reserved unless otherwise indicated. Contact the author(s) for any necessary permissions. Learn more at https://escholarship.org/terms

Peer reviewed 


\section{¿Qué es lo neofantástico?}

La historia de la literatura está jalonada por conceptos o abstracciones que intentan definir su curso y trazar un mapa de sus direcciones y de sus isobaras. Esa terminología es acuñada, a veces, por el mismo movimiento que produce un grupo de obras y que las identifica desde los colores de su bandera: modernismo, surrealismo, existencialismo, etc. Esto en lo que respecta a un período literario o movimiento. Mucho más resbaladizo es el terreno de los géneros literarios, que requiere un conjunto de obras afines antes de poder acotarlas en una poética o retórica. La dificultad nace, justamente, de ese esfuerzo por definir común denominadores en obras aparentemente heterogéneas y sin un nexo afin. Más allá de su brevedad, ¿qué homologa a las narraciones cortas de la Biblia, Las mil y una noches y el Decamerón con los cuentos modernos que comienzan a escribirse de Edgar Allan Poe en adelante? En este caso, es evidente que la brevedad por sí sola no basta para fijar un criterio genérico. El cuento moderno, tal como lo entendemos a partir de Poe, que elabora la primera poética del género, difiere considerablemente en su concepción, organización y funcionamiento de formas allegadas que le preceden. Con Poe, el relato breve adquiere una tesitura, una concentración y estructura que no tenían sus prolegómenos. Poe define no solamente lo peculiar de su longitud - texto que se lee de una sentada-, sino otros rasgos distintivos: el efecto singular, por ejemplo, que controla y determina la disposición del argumento, que fija la composición del texto y que establece interrelaciones entre sus partes. Desde esos rasgos, Poe vertebró una forma que se distingue radicalmente de otras formas breves que le anteceden. Desde Poe no podemos hablar indiscriminadamente de "cuentos" para referirnos a narraciones breves: será cuento solamente aquel que se avenga a la preceptiva fijada por el maestro norteamericano. No se trata de una fórmula o de una matriz rígida e inviolable. Un criterio tan estrecho invalidaría como cuentos formas posteriores que se desvían del modelo establecido por Poe; pero desde Poe el relato breve adquiere una fisonomía, una coherencia y un equilibrio estructural que excluye formas invertebradas, anteriores o 
posteriores. Y si para las primeras reservamos el nombre de cuentos, hablamos de las segundas como "relatos".

Mucho menos claro ha sido el caso del género fantástico. Si respecto al cuento, su sola brevedad confundió o equivocó a muchos - se definió como cuentos relatos que por su extensión podrían serlos pero que por todos sus otros rasgos se resistían a entrar en esa categoría-, respecto al relato fantástico la presencia de un elemento fantástico en una obra perfectamente realista bastó para que habláramos de literatura fantástica. En Hispanoamérica, y en particular en la Argentina, la denominación "literatura fantástica" se ha empleado con ambigüedad excesiva. En su estudio El cuento fantástico, de 1968, Emilio Carilla anota: "Porque es evidente que bajo la denominación de literatura fantástica abarcamos un mundo que toca, en especial, lo maravilloso, lo extraordinario, lo sobrenatural, lo inexplicable. En otras palabras, al mundo fantástico pertenece lo que escapa, o está en los límites, de la explicación 'científica' y realista; lo que está fuera del mundo circundante y demostrable" (20). Nótese el sentido lato con que Carilla maneja la idea de lo fantástico. Para definir lo fantástico recurre a nociones como "lo maravilloso" y "lo extraño" (lo inexplicable) que constituyen géneros autónomos y diferenciados de lo fantástico propiamente dicho. Con la misma libertad se sugiere que "el primer relato fantástico propiamante dicho, en la Argentina, es el Santos Vega de Mitre" (Cócaro 13), o, tal vez, el remoto poema de Barco Centenera, $L a$ Argentina, del siglo XVII (Barrenechea ix-X). Un criterio tan voluble del género abre sus puertas a cualquier texto que contenga un elemento de maravilla. Literatura fantástica serían, así, Homero y Shakespeare, Cervantes y Goethe. Definir como literatura fantástica una obra por la mera presencia de un elemento fantástico es inconducente; equivaldría a definir una obra como tragedia solamente porque contiene uno o más elementos trágicos, o a definir un cuento por la brevedad de su texto. $\mathrm{O}$, como observa Alfonso Reyes en El deslinde respecto al texto literario en general: "El aleteo de algunas furtivas frases literarias en una obra no literaria no basta para definir a esa obra como literaria" (33).

La definición de una forma literaria busca facilitar el estudio de esa forma, comprender sus posibilidades y límites y distinguir su función y funcionamiento de formas semejantes. Solamente en las últimas décadas, desde el pionero estudio de P. G. Castex, El cuento fantástico en Francia, de 1951, la literatura fantástica ha sido objeto de un estudio más sistemático. ${ }^{1}$ Según algunos de estos estudios, mucho de lo que hemos dado en llamar "literatura fantástica", no lo sería. ¿Qué distingue y separa al género fantástico de géneros vecinos o afines? La mayor parte de los críticos que se plantean este interrogante coinciden en señalar la capacidad del género de generar algún miedo $u$ horror. Para Louis Vax, por ejem- 
plo, "el arte fantástico debe introducir terrores imaginarios en el seno del mundo real.... Lo sobrenatural, cuando no trastorna nuestra seguridad, no tiene lugar en la narración fantástica"' (1960:6).

Roger Caillois coincide con Vax y define la literatura fantástica como "un juego con el miedo". Para salvar la distancia que media entre el mundo sobrenatural de las hadas y los milagros y nuestro mundo regido por leyes inmutables establecidas por las ciencias, Caillois propone dos conceptos diferenciantes - lo maravilloso y lo fantástico-, para explicar:

El universo de lo maravilloso está naturalmente poblado de dragones, de unicornios y de hadas; los milagros y las metamorfosis son allí continuos; la varita mágica, de uso corriente; los talismanes, los genios, los elfos y los animales agradecidos abundan; las madrinas, en el acto, colman los deseos de las huérfanas meritorias... En lo fantástico, al contrario, lo sobrenatural aparece como una ruptura de la coherencia universal. El prodigio se vuelve aquí una agresión prohibida, amenazadora, que quiebra la estabilidad de un mundo en el cual las leyes, hasta entonces, eran tenidas por rigurosas e inmutables. Es lo imposible, sobreviniendo de improviso en un mundo de donde lo imposible está desterrado por definición (11).

Caillois ilustra la mecánica y los efectos de estos dos géneros con un ejemplo muy persuasivo. Toma el romance medieval de los Tres Deseos, difundido en toda Europa, y que en Francia se conoce en la versión clásica de Charles Perrault, y lo confronta con lo que podría considerarse su versión moderna, el cuento del escritor inglés William W. Jacobs, "The Monkey's Paw" (La pata del mono). Recordemos muy brevemente el relato de Perrault:

Un leñador socorre a un hada, quien como recompensa le concede la realización inmediata de tres deseos a su elección. Maravillado, y con su mujer, se lanza a la búsqueda de los tres deseos más provechosos. Atolondradamente, ante la escasa porción de carne que se le sirve, desea en alta voz una morcilla humeante de una vara de largo, la que aparece inmediatamente. Un deseo perdido. La mujer, irritada, pide que la morcilla se quede pegada a la nariz del campesino imprudente, lo que en seguida se realiza. El segundo deseo ha sido así despilfarrado y no queda más recurso que utilizar el tercer deseo para librar al desdichado leñador de la morcilla que lo desfigura (Caillois 12-13).

La versión del tema en el cuento de Jacobs es una viñeta de la vida moderna: la casa de una pareja de jubilados, en una noche de invierno, con el hogar encendido, el padre y su único hijo, ya mayor, juegan al ajedrez junto al fuego mientras la mujer teje plácidamente cerca de la chimenea y todos esperan a un huésped que finalmente llega a pesar de la noche fría, 
húmeda y de mucho viento. La visita, el sargento Morris, les presenta una pata de mono investida de poderes mágicos por un viejo faquir de la India: tres hombres pueden pedirle tres deseos. Esa misma noche, después que el sargento deja la casa, el padre, incrédulo, pide, a instancias de su mujer, doscientas libras para pagar la hipoteca de la casa. El sargento les había advertido que las "cosas ocurrían con tanta naturalidad que parecían coincidencias". A la mañana siguiente y hacia el mediodía un representante de la fábrica donde trabaja el hijo viene a informarles que al hijo lo agarraron las máquinas hiriéndolo de muerte. La compañia niega toda responsabilidad en el accidente, pero en consideración a los servicios prestados por el hijo le remiten doscientas libras. El primer deseo ha sido cumplido.

Una semana después, en medio de la noche, la mujer, abatida por la pérdida, le pide al marido: "Sólo hemos pedido un deseo. Le pediremos otro más. Busca la pata y pide que nuestro hijo vuelva a la vida". El marido, que ha visto el cuerpo destrozado e irreconocible del hijo, le recrimina "Estás loca", pero finalmente asiente, y pide: "deseo que mi hijo viva de nuevo". Imposible reproducir la atmósfera de terror y miedo gótico que suscita el relato. Baste decir que en la oscuridad opresiva ("la vela se había consumido"), el frío cortante, los golpes furtivos en la puerta de entrada y la mujer que enajenada baja del cuarto a abrir la puerta (al hijo que vuelve), el marido sólo piensa en cómo evitar el pavoroso e inaudito encuentro con la horripilante figura del hijo destrozado. Toma la pata de mono y frenéticamente balbucea el tercer y último deseo. Los golpes cesan y al abrir la puerta, "el camino estaba desierto y tranquilo".

"La estructura de los dos relatos", explica Caillois

es estrictamente paralela. No obstante, atendiendo al detalle, no hay entre ellos únicamente la diferencia que existe entre lo divertido y lo atroz. Un contraste fundamental opone las condiciones mismas de una y otra aventura. Tres prodigios que violan el orden natural de las cosas marcan la decepción de los campesinos en el cuento popular. En el relato de Jacobs, la influencia del talismán fantástico, la pata de mono, que gobierna el desarrollo de los hechos, no es legible más que en un encadenamiento de causas que no obstante permanecen equívocas. Los tres deseos son satisfechos sin ruptura manifiesta del orden del mundo: un accidente en una fábrica, el pago de una indemnización, los golpes dados a la puerta de una casa durante la noche. Todo se explica sin duda por el poder maléfico de la pata de mono, pero quien no estuviera en el secreto, quien omitiera el poder de la reliquía fatal, no descubriría en el drama más que coincidencias y autosugestión. Sin embargo, en las leyes inmutables del universo cotidiano se ha producido una fisura, minúscula, imperceptible, dudosa, suficiente no obstante para abrir paso a lo espantoso (13-14). 
En un mundo domesticado por las ciencias, el relato fantástico abre una ventana a la tinieblas del más allá - como una insinuación de lo sobrenatural-, y por esa apertura se cuelan el temor y el escalofrío. Tal escalofrío no se da en el relato de Perrault y no puede darse en el reino de lo maravilloso en general donde la ciencia es todavía una maravilla más y la realidad misma no es menos mágica y maravillosa que las magias y maravillas que pueblan los cuentos de hadas. Por eso, para Caillois, lo fantástico "no podría surgir sino después del triunfo de la concepción científica de un orden racional y necesario de los fenómenos, después del reconocimeinto de un determinismo estricto en el encadenamiento de las causas y los efectos. En una palabra, nace en el momento en que cada uno está más o menos persuadido de la imposibilidad de los milagros. Si en adelante el prodigio da miedo es porque la ciencia lo destierra y porque se lo sabe inadmisible, espantoso" (12).

Tal momento ocurre entre los años 1820 y 1850 cuando, según Caillois, este género inédito distribuyó sus obras maestras: Hoffmann nace in 1778; Poe y Gogol en 1809. Entre esas dos fechas nacen William Austin (1778), Achim von Arnim (1781), Charles Robert Maturin (1782), Washington Irving (1785), Balzac (1799), Hawthorne (1803) y Mérimée (1805), o sea, todos los primeros maestros del género. Dickens (1812), Sheridan le Fanu (1814) y Alexis Tolstoi (1817) siguen de cerca.

En mayor o menor medida, casi todos los críticos que han estudiado el género coinciden en definir lo fantástico por su capacidad de generar miedo en el lector. H. P. Lovecraft lo dice rotundamente: "Un cuento es fantástico simplemente si el lector experimenta profundamente un sentimiento de temor y de terror, la presencia de mundos y poderes insólitos" (16). También Peter Penzoldt ha insistido en que "a excepción del cuento de hadas, todos los relatos sobrenaturales son historias de miedo" (9). Y a pesar de la boutade de Todorov, en el sentido de que si para determinar lo fantástico el sentimiento de miedo debe asaltar al lector, "habrá que concluir que el género de una obra depende de la sangre fría del lector" (40), puesto a definirlo restaura el horror o el miedo como el efecto hacia el cual avanza toda la maquinaria del relato, como su inevitable razón de ser. El miedo era una forma de cuestionar la infalibilidad del orden racional: ocurre lo que no puede ocurrir, lo imposible deviene posible, sin violar el orden científico de la realidad se le hace una zancadilla y se le obliga a ceder. O, como ha explicado Caillois, "lo fantástico supone la solidez del mundo real, pero para poder mejor devastarlo... Aparece apenas antes del siglo XVIII, contemporáneo del Romanticismo, y a manera de compensación de un exceso de racionalismo" (21).

Si lo fantástico es reconocible e identificable desde ese efecto que todos los críticos del género han definido como su rasgo distintivo, ¿cómo clasificar y nombrar aquellos relatos que contienen elementos fantásticos pero 
que no se proponen asaltarnos con algún miedo o terror? ¿Cómo definir algunas narraciones de Kafka, Borges o Cortázar, de indiscutible relieve fantástico pero que prescinden de los genios del cuento maravilloso, del horror del relato fantástico o de la tecnología de la ciencia ficción? Por supuesto que no se trata de una mera taxonomía. Se trata de una comprensión más a fondo de sus propósitos y alcances; se trata de fijar una visión que justifique su funcionamiento; se trata, en resumen, de establecer una poética de este tipo de relato que nos impresiona como fantástico (ya que no hay hombres que se conviertan en insectos o axolotls o que sean inmortales), pero que difiere radicalmente del cuento fantástico tal como lo concibe y practica el siglo XIX.

Cortázar fue el primero en expresar su insatisfacción respecto al rótulo generalizado. En su conferencia en La Habana, ya en 1962, decía a propósito de la filiación genérica de sus relatos breves: "Casi todos los cuentos que he escrito pertenecen al género llamado fantástico por falta de mejor nombre" (1962:3). Lector apasionado de la literatura gótica y devoto traductor de dos volúmenes de cuentos de Poe, sabía demasiado bien que a pesar de los trazos fantásticos que contenían sus cuentos (un personaje que vomita conejos, una familia que cohabita con un tigre, inexplicables ruidos que desalojan de la casa a una pareja de hermanos), no eran relatos fantásticos. Eran otra cosa: un nuevo tipo de ficción en busca de su género. En 1975, en las conferencias en Norman, Oklahoma, ratificó y amplió esa sospecha del 62 respecto al género de sus relatos. Reconoce lo que su narrativa debe a los maestros de lo fantástico y lo que la sitúa en otro plano, dentro de un género nuevo que si derivó de aquél, responde, en cambio, a una percepción y a una poética diferentes. Oigamos:

Las huellas de escritores como Poe están innegablemente en los niveles más profundos de mis cuentos, y creo que sin "Ligeia", sin "La caída de la casa de Usher", no hubiera tenido esa disposición hacia lo fantástico que me asalta en los momentos más inesperados y que me lanza a escribir como la única manera de cruzar ciertos límites, de instalarme en el territorio de lo otro. Pero algo me indicó desde el comienzo que el camino hacia esa otredad no estaba, en cuanto a la forma, en los trucos literarios de los cuales depende la literatura fantástica tradicional para su celebrado "pathos", que no se encontraba en la escenografía verbal que consiste en desorientar al lector desde el comienzo, condicionándolo con un clima mórbido para obligarlo a acceder dócilmente al misterio y al miedo... La irrupción de lo otro ocurre en mi caso de una manera marcadamente trivial y prosaica, sin advertencias premonitorias, tramas ad hoc y atmósferas apropiadas como en la literatura gótica o en los cuentos actuales de mala calidad... Así llegamos a un punto en que es posible reconocer mi idea de lo fantástico dentro de un registro más amplio y más abierto que el predomi- 
nante en la era de las novelas góticas y de los cuentos cuyos atributos eran los fantasmas, los lobo-humanos y los vampiros (1983:66-67).

Es evidente el esfuerzo de Cortázar por deslindar el territorio de lo que él llama "lo fantástico tradicional" de ese otro en el que habita su obra. No le interesaba el primero, que había dado su medida en el siglo XIX, pero que continuaba repitiendo sus trucos y fórmulas en el XX. Se lo dijo sin ambages a Ernesto González Bermejo en 1978:

Mientras hay un público inmenso que admira los cuentos fantásticos de Lovecraft — público que se sentirá horrorizado por lo que voy a decir-, a mí personalmente no me interesan en absoluto porque me parece un fantástico totalmente fabricado y artificial... Lovecraft empieza por crear un decorado que ya es fantástico pero anacrónico, parece cosa del siglo XVIII o XIX. Todo sucede en viejas casas, en mesetas azotadas por el viento o en pantanos con vapores que invaden el horizonte. Y una vez que consiguió aterrorizar al lector ingenuo, empieza a soltar unos bichos peludos y maldiciones de dioses misteriosos, que estaban muy bien hace dos siglos, cuando eso hacia temblar a cualquiera, pero que actualmente, por lo menos para mí, carece de todo interés. Para mí lo fantástico es algo muy simple, que puede suceder en plena realidad cotidiana, en este mediodía de sol, ahora entre Ud. y yo, o en el Métro, mientras Ud. venía a esta entrevista (42).

Como Borges y Bioy Casares, que en su Antología de 1940 mezclaron relatos de géneros y períodos varios bajo la denominación "fantástica", también Cortázar - con incomodidad, con reservas y aclaraciones- siguió empleando ese término, que define un género muy particular, para nombrar ficciones que se apartan considerablemente de los propósitos, técnicas y manejo del género fantástico. Y como Cortázar, también Bioy, en su prólogo a la Antología de 1940, reconoció que el término "fantástico" que los antologistas empleaban para narraciones tan diferentes en aproximación y tan distantes en el tiempo se prestaba a malentendidos y equívocos. Bioy aclara que "no hay un tipo, sino muchos, de cuentos fantásticos"; y reconoce que "como género más o menos definido, la literatura fantástica aparece en el siglo XIX y en el idioma inglés" (7-8).

Quedaba claro que los cuentos de un Borges, de un Cortázar y, para el caso, de un Kafka, muy poco tenían que ver con el género fantástico como se concibió en el siglo XIX y como lo seguían practicando en el XX algunos escritores pasatistas a lo Lovecraft quien, naturalmente, definía la ficción fantástica por su voluntad aterrorizadora. Kafka, en cambio, quedaba excluido de las antologías que se ajustaban a un criterio estricto y minimalista del género, como la de Roger Caillois. Louis Vax y Tzvetan Todorov coinciden en excluir "La metamorfosis" como espécimen de lo fantástico. El primero concluye que ese cuento, "antes que al género 
fantástico, corresponde al psicoanálisis y a la experiencia mental... Su aventura es más trágica que fantástica" (1965:85). Y Todorov aclara respecto al mismo texto: "El discurso fantástico parte de una situación perfectamente natural para alcanzar lo sobrenatural, mientras que ' $\mathrm{La}$ metamorfosis' parte de un acontecimiento sobrenatural para darle, en el curso del texto, un aire más y más natural... Kafka trata lo irracional como parte del juego: todo su mundo obedece a una lógica onírica que nada tiene que ver con lo real... El discurso kafkiano abandona lo que hemos definido como la segunda condición de lo fantástico: la vacilación representada en el interior del texto (entre lo extraño y lo maravilloso) y que caracteriza más particularmente los ejemplos del siglo XIX" (180-183).

Mientras la crítica fue registrando el alejamiento de la obra de Kafka del género fantástico, resultó más claro que se acercaba a un tipo de relato fantástico más próximo a la definición de Cortázar que a la de Caillois, Vax y Todorov. Walter Benjamin había dicho respecto al autor de El proceso: "No tenemos la doctrina que las parábolas de Kafka interpretan" (122). Quería decir que sus parábolas trascendían nuestras coordenadas lógicas y que nuestros códigos racionales eran insuficientes para descifrar sus metáforas. Naturalmente. Respondían a una visión de la realidad inédita todavía, una realidad "maravillosa", como la llama Cortázar, para explicar: "Maravillosa en el sentido de que la realidad cotidiana enmascara una segunda realidad que no es ni misteriosa, ni trascendente, ni teológica, sino que es profundamente humana, pero que por una serie de equivocaciones ha quedado como enmascarada detrás de una realidad prefabricada con muchos años de cultura, una cultura en la que hay maravillas pero también profundas aberraciones, profundas tergiversaciones" (García Flores 10-11). Y si todo el mundo de Kafka obedece a una lógica onírica -como decía Todorov-, esas imágenes surreales no han sido acuñadas para provocar miedos o terrores sino para cartografiar esa realidad segunda de la que hablaba Cortázar y cuya doctrina no ha sido postulada todavía excepto desde esas parábolas y metáforas de la literatura.

A esas imágenes de la otredad alude Cortázar en su definición de lo fantástico: "Para mí lo fantástico" —explica_- "es la indicación súbita de que, al margen de las leyes aristotélicas y de nuestra mente razonante, existen mecanismos perfectamente válidos, vigentes, que nuestro cerebro lógico no capta pero que en algunos momentos irrumpen y se hacen sentir" (González Bermejo 42). No son intentos que busquen devastar la realidad conjurando lo sobrenatural -como se propuso el género fantástico en el siglo XIX-, sino esfuerzos orientados a intuirla y conocerla más allá de esa fachada racionalmente construida. Para distinguirlos de sus antecesores del siglo pasado propuse la denominación "neofantásticos" para este tipo de relatos. Neofantásticos porque a pesar de pivotear alrededor de un elemento fantástico, estos relatos se diferencian de sus abuelos de siglo XIX por su visión, intención y su modus operandi. 
Vamos a tratar muy brevemente cada uno de estos elementos. Por su visión, porque si lo fantástico asume la solidez del mundo real - aunque para "poder mejor devastarlo", como decía Caillois-, lo neofantástico asume el mundo real como una máscara, como un tapujo que oculta una segunda realidad que es el verdadero destinatario de la narración neofantástica. La primera se propone abrir una "fisura" o "rajadura" en una superficie sólida e inmutable; para la segunda, en cambio, la realidad es - como decía Johnny Carter en "El perseguidor" - una esponja, un queso gruyère, una superficie llena de agujeros como un colador y desde cuyos orificios se podía atisbar, como en un fogonazo, esa otra realidad. Borges lo dice de otra manera. Su ensayo "Avatares de la tortuga" concluye con la siguiente reflexión: "Nosotros hemos soñado el mundo. Lo hemos soñado resistente, misterioso, visible, ubicuo en el espacio y firme en el tiempo; pero hemos consentido en su arquitectura tenues y eternos intersticios de sinrazón para saber que es falso" (156). Gran parte de la obra de Borges se nutre de esas paradojas que, como la de Zenón de Elea, son intersticios de sinrazón, momentos de insomnio del sueño de la razón.

En lo que toca a la intención, el empeño del relato fantástico dirigido a provocar un miedo en el lector, un terror durante el cual trastabillan sus supuestos lógicos, no se da en el cuento neofantástico. Ni "La Biblioteca de Babel", ni "La metamorfosis" ni "Bestiario" nos producen miedo o temor. Una perplejidad o inquietud sí, por lo insólito de las situaciones narradas, pero su intención es muy otra. Son, en su mayor parte, metáforas que buscan expresar atisbos, entrevisiones o intersticios de sinrazón que escapan o se resisten al lenguaje de la comunicación, que no caben en las celdillas construidas por la razón, que van a contrapelo del sistema conceptual o científico con que nos manejamos a diario. La primera frase de "La Biblioteca de Babel" declara su intención metafórica: "El universo (que otros llaman la Biblioteca)...' Para definir el caos del universo, Borges escoge, como vehículo de la metáfora, su antípoda, una biblioteca que representa la ordenación del conocimiento humano, pero la afantasma poblándola con libros ilegibles. Lo insólito de su condición constituye, sin embargo, su mensaje más poderoso: si una biblioteca representa la ordenación del conocimiento humano, ese orden es un orden ficticio; el orden del mundo real, en cambio, es opaco, ilegible, caótico, como la Biblioteca de Babel.

También en los cuentos de Cortázar el elemento fantástico - los ruidos de "Casa tomada", el tigre de "Bestiario" y los conejos de "Carta a una señorita en Paris" - son portadores de un sentido metafórico. Su irrupción en el relato no son arbitrios o desboques de la imaginación. Constituyen la resolución metafórica a las situaciones y conflictos planteados en el cuento. Ese lenguaje segundo - la metáfora - es la única manera de aludir a una realidad segunda que se resiste a ser nombrada por el lenguaje de la comunicación. La metáfora corresponde a la visión y descripción de esos 
agujeros en nuestra percepción causal de la realidad. Adoptando un término acuñado por Umberto Eco en Obra abierta propuse llamarlas "metáforas epistemológicas". ${ }^{2}$ Para Eco aludían a la condición de las obras de arte como complementos del conocimiento científico y, por lo tanto, no podían decir nada que no estuviera ya dicho por las ciencias: el canal más autorizado, para Eco, del conocimiento del mundo. Mi uso del concepto es más restringido y difiere del sentido atribuido por Eco. Llamo metáforas epistemológicas a esas imágenes del relato neofantástico que no son "complementos" al conocimiento científico sino alternativas, modos de nombrar lo innombrable por el lenguaje científico, una óptica que ve donde nuestra visión al uso falla. Las he definido también como una geometría no euclidiana que puede superar los límites y cortedades de la geometría euclidiana. Es evidente que la transformación de Gregorio Samsa en insecto en el cuento de Kafka obedece a una intención metafórica: su problemática relación con su familia, su soledad y alienación no están explicadas sino desde su metamorfosis. "Nadie puede saber qué es un animal, qué ve o qué siente" — decía Cortázar (1978:39). Hay una cierta opacidad en la metáfora de Kafka, como la hay en el axolotl de Cortázar. Pero si supiéramos qué siente el insecto o qué ve un axolotl mucha de la eficacia de las dos conversiones se hubiera perdido. Esa deliberada ambigüedad define otro rasgo de estas metáforas: lo incierto de sus tenores $\mathrm{y}$, a veces, su condición de innombrables. "Casa tomada" admite una multiplicidad de interpretaciones según el sentido que atribuyamos a los enigmáticos ruidos: masas peronistas, chismes de vecinos o dolores del parto. Estas interpretaciones son ajenas al relato mismo. El texto se calla, pero ese silencio o ausencia es, frecuentemente, su más poderosa declaración.

Finalmente, en lo que toca a la mecánica o modus operandi de estas narraciones hay que decir que se diferencian considerablemente del cuento fantástico. Todorov tenía razón cuando objetaba al relato de Kafka que "el acontecimiento extraño no apareciera después de una serie de indicaciones indirectas como la suma de una gradación y que estuviera ya contenido en la primera frase del relato". Y explicaba: "El discurso fantástico parte de una situación perfectamente natural para alcanzar lo sobrenatural..., mientras que 'La metamorfosis' parte de un acontecimiento sobrenatural para darle, en el curso del texto, un aire más y más natural... El discurso kafkiano abandona lo que hemos definido como la segunda condición de lo fantástico: la vacilación representada en el interior del texto" (183). Naturalmente, no le interesa asaltar al lector con esos miedos que constituyen la razón de ser del cuento fantástico. Para que ese miedo se produzca, la narración fantástica asume la causalidad del mundo, reproduce la realidad cotidiana tal como la conocemos en el comercio diario con la vida y monta una maquinaria narrativa que gradual y sutilmente la socava hasta ese momento en que esa misma causalidad de la que se partió cede y ocurre, o pareciera que va a ocurrir, lo imposible: el hijo muerto 
destrozado por las máquinas de "La pata de mono" golpea a la puerta de la casa de los padres. El relato neofantástico prescinde también de los bastidores y utilería que contribuyen a la atmósfera o pathos necesaria para esa rajadura final. Desde las primeras frases del relato, el cuento neofantástico nos introduce, a boca de jarro, al elemento fantástico: sin progresión gradual, sin utilería, sin pathos: "Hubo un tiempo en que yo pensaba mucho en los axolotl. Iba a verlos al acuario del Jardin des Plantes y me quedaba horas mirándolos, observando su inmovilidad, sus oscuros movimientos. Ahora soy un axolotl"' (1964:161). Pero mientras el cuento fantástico se mueve en el plano de la literalidad, de los hechos históricos del argumento - los golpes furtivos que se oyen en la puerta de la casa de la pareja jubilada en "La pata de mono", corresponden, en efecto, al regreso histórico del hijo muerto-, el relato neofantástico alude a sentidos oblicuos o metafóricos o figurativos: no es Nico, el hermano muerto del personaje de "Cartas de mamá", quien reaparece al final del cuento, sino la proyección de Nico en la conciencia acosada por la culpa y el remordimiento de Laura y Luis. Tampoco es Pierre, en "Las armas secretas", una reencarnación del soldado alemán que violó a Michèle - como más de un comentarista ha interpretado-; Michèle proyecta su trauma de la violación en la persona de Pierre; la metamorfosis de Pierre a lo largo del relato va registrando, como en un espejo, los ángulos, aristas y circunstancias del trauma de Michèle. Pierre se convierte en el soldado alemán, pero solamente como una metáfora del trauma de Michèle, no en el plano histórico como en los cuentos fantásticos, aunque el relato no lo declare así.

Digamos finalmente que si el cuento fantástico es, como ha señalado Caillois, contemporáneo del movimiento romántico y como éste un cuestionamiento y un desafío del racionalismo científico y de los valores de la sociedad burguesa, el relato neofantástico está apuntalado por los efectos de la primera guerra mundial, por los movimientos de vanguardia, por Freud y el psicoanálisis, por el surrealismo y el existencialismo, entre otros factores.

Propuse la denominación neofantástico como un llamado de atención de las diferencias que he señalado entre esos dos tipos de narración. También porque la toma de conciencia de esas diferencias permitiría una mejor comprensión de los sentidos y alcances del nuevo género y un estudio más cabal y concienzudo de sus textos. La vaguedad nunca ha sido beneficiosa para el estudio de la literatura. "Las especificidades nos ayudan mucho más que las generalidades", adviritió en una ocasión Harry Levin. He buscado en esta inquisición ser leal y consecuente con ese espíritu.

Voy a terminar con un detalle de cronología. A pesar de que yo venía trabajando en este problema desde 1971, año en que inicié las investigaciones para mi libro En busca del unicornio, mi primera comunicación escrita enunciando la necesidad de distinguir los dos géneros apareció en la revista Dada/Surrealismo, publicada en Nueva York por la Asociación de 
ese nombre, en 1975, y leída en la reunión anual de esa sociedad en 1974. Hablaba ya allí del manejo de lo fantástico por los escritores neofantásticos diferente del practicado por los maestros de lo fantástico tradicional. El título de ese breve trabajo definía ya el bulbo del nuevo género: lo fantástico como metáforas surrealistas. En 1978, leí un trabajo en el coloquio anual sobre Métodos Contemporáneos de Análisis Literario, en Nueva York, que se titulaba "Literatura neofantástica: una respuesta estructuralista" y que se proponía esbozar un método de estudio para estas ficciones que se resisten a la llamada “crítica de la traducción". En 1979, invitado por la Universidad de Puerto Rico, pude resumir, en un cursillo titulado "Cortázar y la literatura fantástica", lo que hasta ese momento había hecho sobre el tema. Finalmente, en 1983, y aunque con algún retraso, apareció mi libro En busca del unicornio: los cuentos de Julio Cortázar; elementos para una poética de lo neofantástico, algunos de cuyos puntos centrales he intentado resumir hoy.

Creo no equivocarme al afirmar que el término ha echado raíces en la crítica. No son pocos los artículos que he podido leer que asumen esa denominación. En 1988 apareció un libro que lleva por título Lo neofantástico en Julio Cortázar. ${ }^{3} \mathrm{Si}$ el concepto ha arraigado es porque, creo, respondía no a ningún antojo bautismal sino a la necesidad de entender los resortes y el funcionamiento de ese nuevo género. Para mí, la prueba más importante del valor que esa terminología pueda tener fue un segmento de la última entrevista a Julio Cortázar. Se la hizo Omar Prego muy poco antes de su muerte. En un rotundo despliegue de inmodestia me permito reproducir el fragmento:

Omar Prego: Generalmente, cuando se habla de los cuentos de Julio Cortázar se piensa de una manera casi automática en lo fantástico. Pero yo me pregunto si tus cuentos pueden ser considerados cuentos fantásticos en el sentido tradicional del género... Casi me quedaría con la definición de Jaime Alazraki que habla de "cuentos neofantásticos".

Julio Cortázar (después de resumir brevemente su sentimiento de lo fantástico): Desde muy pequeño, hay ese sentimiento de que la realidad para mí era no solamente lo que me enseñaba la maestra y mi madre y lo que yo podía verificar tocando y oliendo, sino además continuas interferencias de elementos que no correspondían, en mi sentimiento, a ese tipo de cosas. Esa ha sido la iniciación de mi sentimiento de lo fantástico, lo que tal vez Alazraki llama neofantástico. Es decir, no es un fantástico fabricado, como el fantástico de la literatura gótica, en que se inventa todo un aparato de fantasmas, de aparecidos, toda una máquina de terror que se opone a las leyes naturales, que influye en el destino de los personajes. No, claro, lo fantástico moderno es muy diferente (53-54).

El resumen de Cortázar define con la precisión, densidad y transparencia que a mí me han faltado qué es y cómo es lo neofantástico. Ahora puedo 
pedirles que me perdonen la farragosa prolijidad y la extensión excesiva de esta charla palabrera. ${ }^{4}$ Lo he dicho mejor en En busca del unicornio y a ese libro los remito.

\author{
Jaime Alazraki \\ Columbia University
}

\title{
NOTAS
}

1. Entre los estudios más útiles véanse: Roger Caillois, Images, images... (París: José Corti, 1966); R. Caillois, Au coeur du fantastique (París: Gallimard, 1959); Marcel Schneider, La littérature fantastique en France (París: Fayard, 1964); Tzvetan Todorov, Introduction à la littérature fantastique (París: Seuil, 1970); Louis Vax, L'art et la littérature fantastiques (París: P.U.F., 1960); Georges Jacquemin, Littérature fantastique (París, 1974); Pierre Mabille, Le miroir du merveilleux (Paris, 1962); H. P. Lovecraft, Supernatural Horror in Literature (New York: Ben Abramson, 1945); Peter Penzoldt, The Supernatural in Fiction (New York: Humanities Press, 1965); Eric S. Rabkin, The Fantastic in Literature (Princeton, 1966).

2. Véase el capitulo "Tlon y Asterión: metáforas epistemológicas" en nuestro libro La prosa narrativa de Jorge Luis Borges (Madrid: Gredos, $3^{\mathrm{a}}$ ed., 1983): 275-301.

3. Véase Julia G. Cruz, Lo neofantástico en Julio Cortázar (Madrid: Pliegos, 1988).

4. Esta conferencia fue pronunciada el 11 de julio de 1990 en el Curso de Verano de la Universidad Complutense de Madrid dedicado a "Las literaturas fantásticas", bajo la dirección de María Kodama y realizado en El Escorial entre el 9 y 13 de julio de 1990.

\section{OBRAS CITADAS}

Barrenechea, Ana María y Emma Susana Speratti Piñero. La literatura fantástica en la Argentina. México, 1957.

Benjamin, Walter. Illuminations. New York: Schocken, 1969.

Borges, Jorge Luis, Silvina Ocampo y Adolfo Bioy Casares. Antología de la literatura fantástica. Barcelona: Edhasa, 1981.

Borges, Jorge Luis. Otras inquisiciones. Buenos Aires: Emecé, 1960.

Caillois, Roger. Imágenes, imágenes. Buenos Aires: Sudamericana, 1970.

Carillo, Emilio. El cuento fantástico. Buenos Aires: Nova, 1968.

Cócaro, Nicolás. Cuentos fantásticos argentinos. Buenos Aires: 1960.

Cortázar, Julio. "Algunos aspectos del cuento." Casa de las Américas 15-16 (1962).

—. "El estado actual de la narrativa en Hispanoamerica." Julio Cortázar: la isla final.

Eds. Jaime Alazraki et al. Madrid: Ultramar, 1983.

. Final del juego. Buenos Aires: Sudamericana, 1964.

Territorios. México: Siglo XXI, 1978.

García Flores, Margarita. "Siete respuestas de Julio Cortázar". Revista de la Universidad de México XXI.7 (1967).

González Bermejo, Ernesto. Conversaciones con Cortázar. Barcelona: Edhasa, 1981.

Lovecraft, H. P. Supernatural Horror in Literature. New York: Ben Abramson, 1945.

Penzoldt, Peter. The Supernatural in Fiction. New York: Humanities Press, 1965.

Prego, Omar. La fascinación de las palabras: conversaciones con Julio Cortázar. Barcelona: Muchnik, 1985.

Reyes, Alfonso. El deslinde. México, 1944.

Todorov, Tzvetan. Introducción a la literatura fantástica. Buenos Aires: Tiempo Contemporáneo, 1972.

Vax, Louis. L'art et la littérature fantastiques. París: P.U.F., 1960.

. Arte y literatura fantásticas. Buenos Aires: Eudeba 1965. 